\title{
Lasers- Hallmark lineage of clinical dentistry
}

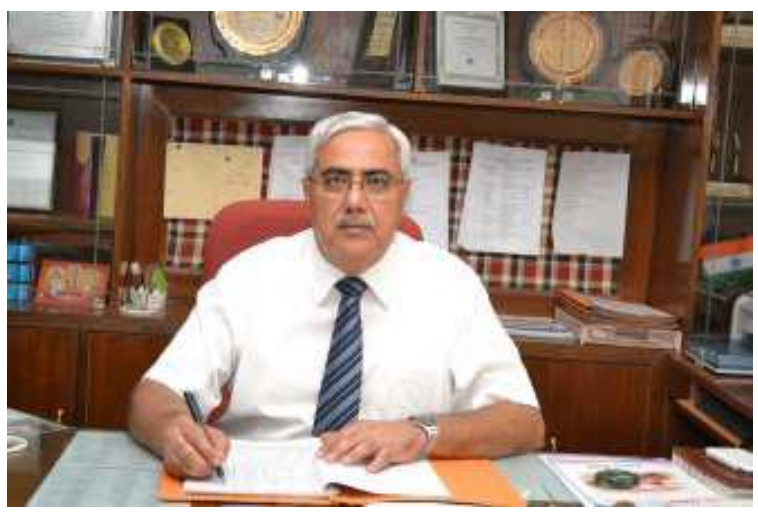

Prof. (Dr.) Vinod Sachdev

Director-PG Studies, I.T.S Centre for Dental Studies and Research, Muradnagar. Editor-in-chief

Dear Readers!

Greetings and welcome to the latest edition of our Journal!

In the past decades starting from Goldman, Sherman and Ruben's vision (1964) of lasers with a spectrographic Medical and Dental use, to the explorative outburst of scientific research into the analysis pitching for, its market potential in a modern day dental practice with the parallel emergence of International forums podcasting the imminent application in the safest manner. Each variety of lasers has its own functional assets, but the principle characteristic is judged by its wavelength, absorption, reflection and most importantly its transmission into the target tissues. ${ }^{1}$ Diodes being the progenitors for soft tissue ablation over Nd:YAG and Er:YAG and Er:YAG for hard tissue, Lasers have found their way into modern clinical scenario with a bang starting from the diagnostic aspect with its quality of laser florescence. ${ }^{2}$ It has also dived in to rescue teeth from caries by laser activated fluoride therapy ${ }^{3}$ and pit $\&$ fissure recontouring. ${ }^{4}$ Lasers have successfully out casted the use of traditional maneuver of cavity preparation, removal of fillings, polymerization, sterilization of root canals or be it sensitive surgical procedures like frenectomy, operculectomy, biopsies, depigmentation, periodontal surgeries, peri-implantitis and socket/pocket debridement, tooth exposure etc. by promising the operator of a complete bloodless, painless, clock instant and most importantly a sterile field to play safe. ${ }^{5}$

Lasers are now a promising viable and available system representing the "NEW BIOLOGIQUE" of Dentistry with a high state of technical refinement in terms of both performance and user friendly at the same time. Realizing the need of the hour to introduce lasers into the latest day high class dentistry, our institute,
I.T.S.C.D.S.R, has not wasted time in acquiring this technology and has incorporated its use to the epitome in each and every aspect of dentistry at graduate as well as post graduate level. Above all, our institution believes in providing highest quality of treatment to our patients and what better can it be than incorporating laser dentistry in routine dental procedures.

I covet you all a marvelous reading experience while you go through the documented research work carefully chosen and crafted specially for your inquisitive side. I am also very grateful to our subscribers who make us stronger with each benefaction or referral and hoping to get a continued response with a greater force for our next issue. I request you to reach out to us in case of any suggestion or query as "Your feedback is important to us".

\section{Regards}

\section{Dr. Vinod Sachdev}

Editor-in-chief

Journal of Dental Specialties

\section{References}

1. Kotlow L. Lasers in Pediatric Dentistry. In: Convissar RA (ed). Principles and Practice of Laser Dentistry. St. Louis: Mosby Elsevier, 2011:12-25.

2. Nokhbatolfoghahaie H, Alikhasi M, Chiniforush N, Khoei F, Safavi N, Zadeh BY. Evaluation of Accuracy of DIAGNOdent in Diagnosis of Primary and Secondary Caries in Comparison to Conventional Methods. J Lasers Med Sci 2013;4(4):159-67.

3. Verheyen P, Moritz A, Walsch LJ. Photopolymerization. In Moritz A. Oral laser Application. Quintessenz VerlagsGmbH, Berlin 2006. p: 139-91.

4. Goharkhay K, Moritz A. Caries prevention. In Moritz A. Oral laser Application. Quintessenz Verlags-GmbH, Berlin 2006. p:193-239.

5. Jawad MM, AbdulQader ST, Zaidan BB, Zaidan AA, AbdulQader IT, Naji AW. An overview: Laser applications in Dentistry. Int J Phatmacol 2011;7(2):189-97. 